\title{
On the time course of negative priming: Another look
}

\author{
LYNN HASHER \\ Duke University, Durham, North Carolina \\ ROSE T. ZACKS \\ Michigan State University, East Lansing, Michigan \\ ELLEN R. STOLTZFUS \\ Kenyon College, Gambier, Ohio \\ and \\ MICHAEL J. KANE and S. LISA CONNELLY \\ Duke University, Durham, North Carolina
}

\begin{abstract}
In two experiments, the pattern of persistence of negative priming effects across delay intervals of 500 and 2,500 msec was assessed using a within-subjects, random sequencing of delays. Neill and Valdes (1992; Neill, Valdes, Terry, \& Gorfein, 1992) have argued that a within-subject experimental design is required for decay of negative priming to be seen, in contrast to results reported elsewhere (e.g., Tipper, Weaver, Cameron, Brehaut, \& Bastedo, 1991) showing stable negative priming effects across delays. In neither experiment was substantial evidence of decay detected, raising questions for the notion that suppression necessarily declines across brief temporal intervals and for the assertion that episodic retrieval is the sole source of negative priming.
\end{abstract}

In this report, we further explore whether "negative priming," a phenomenon that has recently become a focal topic in selective attention research, decays over a few seconds. Negative priming is the finding that, relative to conditions in which targets and distractors are unrelated across successive trials, participants are slowed in responding to the identity of a target stimulus that has just served as a distractor or to the location of a target stimulus that has just held a distractor (e.g., Neill, 1977; Tipper, 1985). On each trial of the experiments described in this paper, for example, participants indicated the location of a target stimulus (an " $\mathrm{O}$ ") while ignoring the location of a distractor stimulus (a "+"). On control trials, the $\mathrm{O}$ and + appeared in different locations on successive trials. On negative priming trials, the target on one "test" trial appeared in the location that had been occupied by the distractor on the preceding "prime" trial. A consistent finding in such a task (e.g., Connelly \& Hasher, 1993; Tipper, Brehaut, \& Driver, 1990) is that participants respond more slowly to the location of the target (and tend to make more errors) on negative priming than on control

The work reported here was supported by Grant AGO 4306 from the National Institute on Aging. We wish to acknowledge the assistance of Cindi May, Julie Dunsmore, and Angela Howell at various stages of this project. M. J. K. is now at the Department of Psychology, University of South Carolina, Columbia. Reprint requests may be sent to L. Hasher, Department of Psychology: Social and Health Sciences, Box 90085, Duke University, Durham, NC 27708-0085 (e-mail: Ihasher@acpub. duke.edu). trials. This slowing has until recently been widely attributed to an attentional inhibitory process. That is, in the process of selecting and responding to a prime target's location (or identity), the representation of distractor location (or identity) and/or response tendencies thereto are actively inhibited or suppressed. The delayed responding to the distractor's location or identity on a subsequent test trial is presumed to be due to the persistence of this inhibitory process (for reviews, see Fox, 1995; May, Kane, \& Hasher, 1995; Neill, Valdes, \& Terry, 1995).

An important parameter of negative priming is the duration over which the effect persists following a selection response. Relatively stable negative priming effects have been reported over "response-to-stimulus" delay intervals (RSIs; measured as the interval between participants' prime-trial response and the test-trial onset) that range, within and across experiments, from 300 to $6,600 \mathrm{msec}$ (Hasher, Stoltzfus, Zacks, \& Rypma, 1991; Stoltzfus, Hasher, Zacks, Ulivi, \& Goldstein, 1993; Tipper, Weaver, Cameron, Brehaut, \& Bastedo, 1991). By contrast, negative priming effects have also been reported to decrease across a similar range of RSIs (Neill \& Valdes, 1992; Neill, Valdes, Terry, \& Gorfein, 1992). Neill and his colleagues (Neill \& Valdes, 1992; Neill et al., 1992; Neill et al., 1995) have noted that studies that show a rapid decline in negative priming use a within-subjects random sequence of RSIs, and studies that show stable negative priming effects use a between-subjects (or between-blocks) manipulation. Neill and his colleagues took this pattern of data as support for an account of negative priming which 
relates the size of the effect to the relative retrievability of information regarding the previous response made to the current target stimulus and to the time required to resolve any conflict between two discrepant response requirements.

According to Neill's alternative account of negative priming (Neill \& Valdes, 1992; Neill et al., 1992; Neill et al., 1995), the target and distractor on a current test trial cue the retrieval of recent processing episodes involving those stimuli, with the likelihood of retrieval generally being greatest for the most recent relevant episode. In the negative priming condition, this most recent episode is the preceding prime trial on which the current target stimulus had served as a distractor. Retrieval of this prior episode carries with it information regarding the responses required to that trial's stimuli and so, on negative priming trials, retrieval will result in a conflict between the "donot-respond" requirement of the prime trial and the "respond" requirement on the current test trial. The resolution of this conflict is then the basis of the slowing called negative priming. In the control condition, by contrast, the current target and distractor are less likely to retrieve an episode in which either item served because such an episode would have occurred relatively long before.

To derive a prediction of a decreasing negative priming function in within-subject but not between-subject RSI manipulations requires some further assumptions. It follows from Neill's and his collaborators' arguments that the probability of retrieving the preceding trial decreases as that trial becomes temporally more discriminable from the current trial, as it does with increasing RSIs. The reduction in similarity between the current trial $(n)$ and its preceding trial $(n-1)$ that occurs as a consequence of the lengthening RSI will lower the chances of retrieval of the information from the preceding trial. In other words, the discriminability between the current and preceding trials will increase as the RSI gets longer, and therefore the probability, on a negative priming trial, of the target's successfully retrieving the $n-1$ episode will decline at longer RSIs. If this were the only factor, however, negative priming should inevitably get smaller with increasing RSI, regardless of whether a within- or a between-subject manipulation of RSI is used.

Neill et al. (1992) thus argue that the key determinant of retrievability (and the attendant conflict on negative priming trials) is more complicated than simply the duration of the RSI. Following arguments made earlier by Baddeley (1976), they suggest that the pattern of RSIs across pairs of trials, particularly the ratio of the most recent RSI (from trial $n-1$ to trial $n$ ) to the one that preceded it (prior, or pRSI, from trial $n-2$ to trial $n-1$ ), is the critical factor in determining the retrievability of the $n-1$ episode. When RSI is varied in blocks or between subjects, the ratio of the current RSI to the one that preceded it is constant for different RSIs and the relative discriminability between successive episodes is therefore fairly constant across a range of RSIs. Thus, since each trial is equally discriminable from its antecedent and retrieval probability (and attendant response con- flict) will not vary across RSIs (Neill et al., 1992), no decay of negative priming would be expected. By contrast, when RSI is varied randomly within subjects, the current RSI will sometimes be shorter than the pRSI and sometimes longer, setting the stage for the differential retrievability of the $n-1$ or preceding trial. In this view, retrieval of the $n-1$, or prime, trial will be determined by how close it is in time to the current trial and how far it is in time from the trial that preceded the prime, the $n-2$ trial. The closer the prime is to the current trial (a short RSI) and the farther from its preceding trial (a long pRSI), the greater the probability of the prime's being retrieved by the probe and the more the negative priming. By contrast, the farther away the prime is from the current trial (a long RSI) and the closer the prime is to its preceding trial (a short pRSI), the less the likelihood of its being retrieved by the current trial and the less negative priming.

In the present paper, we assess the reliability of the different decay findings for between- versus within-subject designs, since these findings are now important for a determination of the mechanism underlying negative priming. As far as we know, the critical RSI/pRSI ratio effects on which Neill's episodic retrieval theory is based have been demonstrated directly in only one published study (Neill et al., 1992, Experiment 1). Because of the importance that inhibition plays as a theoretical construct in current cognitive theory, and because inhibition is the major competing explanation of the negative priming effect, we thought it useful to explore the robustness of the Neill et al. findings. At the very least, this study offers an opportunity to further explore one of the presumably fundamental determinants of negative priming (Fox, 1995; May et al., 1995; Neill et al., 1995).

In these experiments, we also considered another variable that has tended to differ between the studies that have found stable versus diminishing negative priming functions across delays. A careful reading of the experiments reveals that in those finding stable negative priming effects relatively brief (i.e., $150-300 \mathrm{msec}$ ) experimentercontrolled presentations of the stimulus displays were used (Hasher et al., 1991; Stoltzfus et al., 1993; Tipper et al., 1991); by contrast, in experiments showing some decay, a procedure in which the stimulus display remains available until the subject responds was used (Neill \& Valdes, 1992; Neill et al., 1992; Neill \& Westberry, 1987). The latter procedure involves longer exposures to the target and distractor stimuli on each trial than is the case in other studies (e.g., an average of about $500 \mathrm{msec}$ in the Neill et al., 1992, experiments). The effect of exposure duration on the time course of negative priming is considered in both experiments reported here.

In sum, this paper reports the results of two experiments in which the time course of negative priming was explored. In both experiments, the time between trials was varied in a within-subjects manner and a manipulation of display duration was included. Also included in both experiments were unusually large participant numbers. To anticipate, one finding is that of detectable amounts of negative priming at even the longest RSIs 
used here, consistent with a growing literature (but see Neill \& Westberry, 1987). Furthermore, our results indicate that even with a randomized, within-subject manipulation of the time intervals, decay of negative priming over several seconds is a far from robust phenomenon. Also, using the data from Experiment 2, we explore the validity of Neill's (Neill \& Valdes, 1992; Neill et al., 1992) noninhibitory, retrieval-based explanation for the negative priming effect.

\section{EXPERIMENTS 1 AND 2}

The task used in the current experiments was one that we and others have used before (e.g., Connelly \& Hasher, 1993; Neill et al., 1992; Tipper et al., 1990). On each trial, participants indicated the location of a target stimulus $(O)$ in a four-location array while ignoring the location of a distractor stimulus $(+)$ that was also present on most trials. The location of the target was indicated with a spatially compatible keypress response. There were two critical types of trial sequences, negative priming and control. On negative priming trials, the current target was in the location occupied by the distractor on the immediately preceding trial. On control trials, the target and distractors were in new, previously unoccupied locations across prime and test trials (a current distractor stimulus never appeared in the previous target's location). Across groups of participants, two display durations were used, an experimenter-controlled brief one $(150 \mathrm{msec})$ and a participant-controlled one in which display offset was triggered by the participants' response. In each exposure condition, two RSIs were used, 500 and $2,500 \mathrm{msec}$, values chosen because decrements in negative priming effects have been reported across such delay intervals (Neill et al., 1992); also, there is one report of a complete absence of negative priming by $2,020 \mathrm{msec}$ (Neill \& Westberry, 1987). Trial types (negative priming vs. control) and RSIs were varied in a randomized, withinsubjects sequence. On this basis alone, decay of negative priming would be anticipated by some investigators (see Neill \& Valdes, 1992; Neill et al., 1992). Another possible outcome, and a potential explanation for the discrepant decay findings in the literature, was to find no decay under brief-exposure-duration conditions (as used by Hasher et al., 1991; Stoltzfus et al., 1993; Tipper et al., 1991) while finding decay under the long-exposure-duration conditions used by the Neill group.

The two experiments reported here differed chiefly in that in Experiment 1 a prime-probe procedure was used for controlling relations between successive trials and in Experiment 2 a continuous trials procedure, referred to as a list procedure, was used. On the basis of earlier work, in which a target identification was used rather than a target-localization response, we expected greater negative priming in the first experiment than in the second (compare Kane, Hasher, Stoltzfus, Zacks, \& Connelly, 1994, with Stoltzfus et al., 1993). Because in all other ways the experiments were identical in procedure, their methods will be described together, although for clarity, and because there are some differences in the analyses performed, their data will be reported separately.

\section{Method}

Participants. The participants in Experiment 1 were 111 young adults, 50 in the short-exposure condition and 61 in the long-exposure condition. The participants in Experiment 2 were a different group of 84 young adults, 54 and 30 in the short- and long-exposure conditions, respectively. Participants were recruited from the undergraduate populations of Duke University and Michigan State University; they received research credit for a course requirement in exchange for their participation.

Materials. In Experiment 1, a paired-trials procedure consisting of a prime trial followed by a test trial was used. On all trials, the participants indicated the location of a target (an "O"), which appeared in one of four locations on a monitor, by pressing a key on the computer keyboard that corresponded to the target's location. On most of the prime trials and all of the test trials, a plus sign (the distractor) appeared in one of the other three locations. In Experiment 2, a list procedure was used in which an unbroken sequence of 528 trials was presented. Seventytwo of those trials contained a target only; 456 contained both a target and a distractor.

In both studies, the stimuli could occur in four possible positions, arranged in a broad, flat V-shape. The four locations were marked by white stickers centered on a monitor such that the widest horizontal distance between two positions measured $45 \mathrm{~mm}$ and subtended approximately $9.46^{\circ}$ of visual angle at a viewing distance of $36 \mathrm{~cm}$. The smallest horizontal distance measured $17 \mathrm{~mm}$ (subtending $3.6^{\circ}$ ), and the vertical distance measured $12 \mathrm{~mm}$ (subtending $2.54^{\circ}$ ). The stimuli themselves (a white " $\mathrm{O}$ " and a plus sign, in 40-column text mode) subtended $1.49^{\circ}$ and $1.17^{\circ}$ vertically and $0.85^{\circ}$ and $1.17^{\circ}$ horizontally, respectively. A small white cross (subtending $1.17^{\circ}$ horizontally and vertically), centered in the middle of this display, served as a fixation point. The background color for all displays was black. The display of all stimuli (except for the four location markers that were affixed to the monitor) and the timing of responses was controlled by a MEL-based computer program. The experiments were run on IBM-compatible 286 or $386 \mathrm{SX}$ computers equipped with enhanced graphics adapter (EGA) monitors.

The critical dependent measure was the amount of time that elapsed before participants correctly identified the target's location. Participants responded by making a keystroke on the computer keyboard. The four response keys $(D, C, K, M)$ were spatially compatible with the four stimulus locations on the video monitor. These keys were covered with blank, white stickers.

Negative priming effects were measured by comparing two types of test trials: negative priming and control. The negative priming effect for any condition equaled the difference in response times between these two types of trials.

Experiment 1 consisted of 528 trials, 264 prime-test pairs, presented randomly to a subject. There were 192 critical prime-test pairs, with 96 negative priming trials and 96 control trials. Half of all prime-test pairs had an RSI of $500 \mathrm{msec}$, and half had an RSI of 2,500 msec. Experiment 2 also consisted of 528 trials presented randomly to a participant as a continuous list. Embedded within this list of trials were 96 critical negative priming trials and 96 control trials. As in Experiment 1, half of each type of trial (negative priming and control) had an RSI of $500 \mathrm{msec}$ and half had an RSI of $2,500 \mathrm{msec}$.

In both experiments, the locations used across trials were counterbalanced so that each of the four locations contained a target and a distractor equally often. Following the reaction time task, vocabulary skills were measured with a difficult multiple-choice test, the Extended Range Vocabulary Test (ERVT; Educational Testing Service, 1976). An initial evaluation of ERVT scores revealed no between-groups differences in either Experiment 1 or Experiment 2,1

Procedure. The participants were tested individually. They were seated in front of the computer at a distance of approximately $36 \mathrm{~cm}$ from the screen. They were shown the stimulus display and the keyboard and were instructed on how to map their keypresses to the visual display to indicate the location of the target. The left and right index 
fingers were positioned over the $\mathrm{C}$ and $\mathrm{M}$ keys; the left and right middle fingers were positioned over the $D$ and $K$ keys. The participants were informed that every display would contain one and only one target, but that some displays would also contain a distractor in one of the three remaining locations. They were told to ignore the distractor, as it was irrelevant to the task, and to try to respond as quickly and accurately as possible.

In Experiment 1, each prime-test pair began with the screendisplayed "Ready?" positioned $16 \mathrm{~mm}$ above the upper location markers. The participant then pressed the space bar to remove the "Ready?" signal from the screen and to initiate the prime trial. In Experiment 2, the experimenter initiated the first display after the participant was fully informed about the task. In both experiments, a fixation cross then appeared for $500 \mathrm{msec}$. Immediately after fixation offset, the prime display appeared and, in the "short-exposure" condition, remained on-screen for $150 \mathrm{msec}$, after which the screen turned blank and remained so until the participant responded. In the "long exposure" condition, the prime display appeared and remained on-screen until the subject responded. For all participants, the onset of the test display followed the response to the prime target at a delay of $500 \mathrm{msec}$ on half of the trials and at a delay of $2,500 \mathrm{msec}$ on the other half of the trials. The fixation cross used for the prime trials also appeared prior to the test trials; it appeared for the $500 \mathrm{msec}$ preceding test onset. Thus, for the 500 -msec RSI condition, the fixation cross coincided with the entire delay interval, while for the $2,500-\mathrm{msec}$ condition, it occurred after the first $2,000 \mathrm{msec}$ had elapsed. The test display then appeared and was presented for either $150 \mathrm{msec}$ (for the short-exposure group) or until the response to the probe target (for the long-exposure group). In Experiment 1, the ready signal appeared after each test trial response and participants initiated the next sequence at their own pace. In Experiment 2, the next trial appeared for the duration set by the exposure condition (short or long), and this sequence was repeated for the entire series of trials, with no pauses between trials other than the randomly ordered delays.

\section{Results}

Experiment 1. An alpha level of .05 is used throughout. After deleting trials on which errors occurred, the median reaction time (RT) was determined for each participant in each condition. The means of median RTs on the test trials of the negative priming and control conditions are shown in Table 1, as are proportions of errors. ${ }^{2}$ A 2 (exposure condition, short vs. long) $\times 2$ (priming, negative priming vs. control) $\times 2$ (RSI, $500 \mathrm{vs.} 2,500 \mathrm{msec}$ ) mixed analysis of variance (ANOVA) was performed on both RT and error data. These are discussed in turn.

The overall negative priming effect of $22 \mathrm{msec}$, calculated as the difference between control and negative priming RTs, was significant $\left[F(1,109)=190.2, M S_{\mathrm{e}}=289.9\right]$. The main effect of RSI was also reliable $[F(1,109)=$ $\left.8.74, M S_{\mathrm{e}}=504.18\right]$ but must be interpreted in the context of the interaction between RSI and exposure-duration condition $[F(1,109)=4.10]$. Basically, RTs in the longexposure condition tested at the 2,500-msec RSI were $10 \mathrm{msec}$ shorter on average than those in the other three conditions, which did not differ from each other. Because the effect was small and did not replicate in Experiment 2, we do not consider it further.

No other effects were significant in the analysis of the RTs in Experiment 1, including the two critical interactions of (1) the priming $\times$ RSI and (2) the priming $\times$ RSI $\times$ exposure condition interactions (both $F \mathbf{s}<1$ ). Thus, the RT data provide no evidence of a decline in the negative priming effect at the longer RSI for either exposure duration.

Error data were analyzed according to the same ANOVA plan that was used for the RT data. The only significant
Table 1

\begin{tabular}{|c|c|c|c|c|c|c|}
\hline \multirow[b]{3}{*}{ Exposures } & \multicolumn{6}{|c|}{ Response to Stimulus Onset Intervals } \\
\hline & \multicolumn{3}{|c|}{$500 \mathrm{msec}$} & \multicolumn{3}{|c|}{$2,500 \mathrm{msec}$} \\
\hline & Priming & Control & Effect & Priming & Control & Effec \\
\hline \multicolumn{7}{|c|}{ Reaction Times: Experiment 1} \\
\hline Short & 454 & 433 & 21 & 453 & 430 & 23 \\
\hline Long & 452 & 431 & 23 & 443 & 421 & 22 \\
\hline Mean & 453 & 432 & 22 & 448 & 426 & 22 \\
\hline \multicolumn{7}{|c|}{ Reaction Times: Experiment 2} \\
\hline Short & 402 & 387 & 15 & 400 & 388 & 12 \\
\hline Long & 429 & 413 & 16 & 2 & 411 & 11 \\
\hline Mean & 412 & 396 & 16 & 408 & 396 & 12 \\
\hline \multicolumn{7}{|c|}{ Error Rates: Experiment 1} \\
\hline Short & .016 & .012 & .004 & .013 & .007 & \\
\hline Long & .020 & .011 & .009 & .016 & .010 & .006 \\
\hline Mean & .018 & .012 & .006 & .015 & .008 & .006 \\
\hline \multicolumn{7}{|c|}{ Error Rates: Experiment 2} \\
\hline Short & .019 & .010 & .009 & .012 & .013 & -.001 \\
\hline Long & .030 & .021 & .009 & .022 & .015 & .007 \\
\hline Mean & .024 & .016 & .008 & .017 & .014 & .003 \\
\hline
\end{tabular}

finding in this analysis was a main effect of priming [mean $=.016$ for negative priming; mean $=.010$ for control; $F(1,109)=13.09, M S_{\mathrm{e}}=.0003582$ ]. The error data thus support the RT data in providing no hint of a decline in negative priming from an RSI of $500 \mathrm{msec}$ to one of $2,500 \mathrm{msec}$, regardless of exposure duration and despite the fact that the delay interval was varied randomly within subjects.

Experiment 2. After deleting trials on which errors occurred, the median RTs on test trials (shown in Table 1, along with errors) were analyzed using the same $2 \times 2$ $\times 2$ mixed ANOVA plan as before. Overall, subjects were faster in the short-exposure (mean $=394 \mathrm{msec}$ ) than in the long-exposure $($ mean $=418 \mathrm{msec})$ condition $[F(1,82)=$ $\left.4.7, M S_{\mathrm{e}}=9509.1\right]$. As expected, RTs were significantly longer in the negative priming than in the control condition, a negative priming effect in this case of $14 \mathrm{msec}$ $\left[F(1,82)=94.2, M S_{\mathrm{e}}=152.4\right]$. No other effects were reliable, including the two interactions that would indicate a partial or complete decay of negative priming [for the priming $\times$ RSI interaction, $F(1,82)=1.9, M S_{\mathrm{e}}=$ 185.02 ; for the priming $\times$ RSI $\times$ exposure condition interaction, $F<1$ ].

Although the overall error rate was low and the differences in error frequency across conditions small, there were three significant effects in the analysis of the error data of Experiment 2. There was a main effect of exposure [short mean $=.023$; long mean $=.014 ; F(1,82)=$ $\left.4.3, M S_{\mathrm{e}}=.000918\right]$, which, taken together with the RT results, indicates something of a speed-accuracy tradeoff across the two exposure conditions. There was also reliable negative priming [negative priming mean $=.020$; control mean $\left.=.015 ; F(1,82)=7.8, M S_{\mathrm{e}}=.000289\right]$, indicating effects for both errors and RTs in this experi- 
ment. Finally, the interaction between priming and RSI was significant $\left[F(1,82)=4.8, M S_{\mathrm{e}}=.000173\right]$. This interaction indicates that negative priming was larger at the 500-msec RSI (mean effect $=.008$ ) than at the $2,500-\mathrm{msec}$ RSI (mean effect $=.002$ ). This is the only significant finding in the two experiments consistent with a decaying negative priming function, although it can be noted that there was a similar numerical trend in the RT data - the average negative priming effects were 16 and $12 \mathrm{msec}$ at the 500 - and 2500 -msec RSIs, respectively ( $p=.17$ for the response time trial type $\times$ RSI interaction reported above). We note that the negative priming effect at the 2,500-msec RSI was, on its own, significant. Thus, consistent with a large literature, there is no suggestion here of a complete "decay" of negative priming.

Summary of main results of Experiments 1 and 2. Robust negative priming effects were obtained in both experiments, and the size of these effects was uninfluenced by the exposure duration of the selection displays. At most, the data provided weak support for the contention that the negative priming associated with a distractor decays significantly over the first few seconds following a response to a target. The single reliable finding supporting this conclusion was for the error data of Experiment 2. If replicable, it suggests that, at least in a within-subjects design, use of a list rather than a prime/probe organization of trials may be a boundary condition for finding decay of negative priming. Note that between-subjects manipulations of RSI do not yield a decline in negative priming even in list organizations (e.g., Hasher et al., 1991; Stoltzfus et al., 1993). With respect to the present data, however, it is clear that the RT effects reported by Neill and his collaborators were only weakly replicated here.

To further explore the possibility of decay of negative priming in Experiment 2, we report the outcome of an additional analysis that examines negative priming as a function of the combination of RSIs on the current trial and on the one that preceded it (the pRSI). ${ }^{3}$ Recall that this analysis was used by Neill et al. (1992) as a test of Neill's (Neill \& Valdes, 1992; Neill et al., 1992; Neill et al., 1995) episodic retrieval account of negative priming.

\section{The Episodic Retrieval View and \\ Additional Analysis of the Experiment 2 Data}

For the present Experiment 2, the logic from Neill et al. (1992) predicts the following order for decreasing magnitude of negative priming effects as function of the sequences of pRSI/RSIs: $2,500 \mathrm{msec} / 500 \mathrm{msec}>500 \mathrm{msec} /$ $500 \mathrm{msec}=2,500 \mathrm{msec} / 2,500 \mathrm{msec}>500 \mathrm{msec} /$ $2,500 \mathrm{msec}$. The mean negative priming effects (negative priming - control trial RTs) for these four sequences of pRSI/RSIs (for Experiment 2) are shown in Table 2. Beyond the small effect of less negative priming for errors at the longer current RSI that was noted earlier, there is little in these data to support the predictions derived from Neill's viewpoint. Although the ordinal pattern of RT effects does reflect Neill's predictions, various approaches to analysis of these data, including planned comparisons and an ANOVA followed by Newman-
Table 2

Negative Priming Effects (in Milliseconds) in Experiment 2 as a Function of the Previous Trial's RSI and the Current Trial's RSI for Short and Long Exposure Conditions

\begin{tabular}{lcccc}
\hline & \multicolumn{4}{c}{ Ratios of Previous RSI to Current RSI } \\
\cline { 2 - 5 } Exposures & $2,500 / 500$ & $500 / 500$ & $2,500 / 2,500$ & $500 / 2,500$ \\
Short & 17 & 17 & 13 & 10 \\
Long & 15 & 14 & 12 & 9 \\
Mean & 16 & 15 & 12 & 9 \\
& & Reaction Times & \\
Short & .007 & .009 & .015 & .001 \\
Long & .004 & .011 & .006 & .003 \\
Mean & .006 & .011 & .007 & .002 \\
\hline
\end{tabular}

Keuls tests, failed to substantiate the predicted inequalities between the 2,500-/500-msec and the 500-/500msec trials or between the $2,500-/ 2,500-\mathrm{msec}$ and the $500-/ 2,500$-msec trials $\left(F_{\mathrm{S}}<1\right.$ for the planned comparisons). As a more liberal test of Neill's hypothesis, a planned comparison was conducted between the two extreme conditions $(2,500-/ 500$-msec trials vs. $500-/ 2,500$ msec trials), but this difference was outside of even a liberal criterion for significance $\left[F(1,83)=2.6, M S_{\mathrm{e}}=\right.$ $1,219.4, p>.10]$.

\section{DISCUSSION}

Taken together, the data from the two experiments reported here allow for a couple of conclusions. First, by itself, a randomized withinsubject manipulation of RSI produces neither a complete decay nor even necessarily a partial decay of negative priming. Indeed, in the present instance, there is some reliable evidence of decline only when a list procedure is used (as in Experiment 2) and then only for error scores, not RTs. No decay effects are apparent when a prime-test procedure is used. Second, we note also that the present data join all others, with a single exception (Neill \& Westberry, 1987), in showing that even when there is some reduction in negative priming across time, the drop-off is not to zero within a matter of a few seconds. Indeed, there is evidence of the occurrence of sustained negative priming after one or more intervening trials of other items (DeSchepper \& Treisman, 1991; see also Tipper et al., 1991). Together, such findings support the suggestion that, once obtained, negative priming has a rather long duration.

However, with respect to the present work, one might consider the theoretical glass half full or half empty. Indeed, our data provided some, albeit weak, support for Neill et al.'s (1992) predictions; (1) a partial decay was detected in the error data from Experiment 2, and (2) the RT effects from the pRSI/RSI analysis were in the right direction. In considering the meaning of our general lack of statistically significant effects, however, we would make the following points: (1) Both experiments here used much larger sample sizes than is typical in this type of research, where the $n$ s typically range from about 10 (e.g., Neill \& Westberry, 1987) to about 20 (e.g., Hasher et al., 1991; Neill \& Valdes, 1992; Neill et al., 1992; Stoltzfus et al., 1993). (2) In our Experiment 2, we used conditions very similar to those used by Neill et al. in their Experiment 1 . The larger sample size in our study would suggest that our data were more reliable. (3) Although our effect size at the shortest RSI $(500 \mathrm{msec}$ ) was smaller than Neill's, and so may have left less room to detect either complete or partial negative priming decay, we would note that the size of our negative priming effect is more typical of the extant literature (e.g., Connelly \& Hasher, 1993; Hasher et al., 1991; Kane et al., 1994; Neill, Lissner, \& Beck, 1990; Stoltzfus et al., 1993; Tipper et al., 1991; Tipper \& Cranston, 1985; Tipper \& McLaren, 1990). (4) Finally, a power analysis determined that our power to detect a $10-\mathrm{msec}$ decline in negative priming between the $2,500-/ 500-\mathrm{msec}$ and $500-/ 2,500-\mathrm{msec}$ 
conditions (which is proportionally equivalent to the decline found by Neill et al., 1992) was over $.80(d=.4 \mathrm{~J}$; minimum correlation between conditions $=.10 ;$ see Maxwell \& Delaney, 1990). Thus, although the Experiment 2 data might be taken to show a nonsignificant trend toward a decrease in negative priming, they provide no statistical support to the critical pRSI/RSI effects that Neill et al. obtained in their Experiment 1.

The observation of sustained, long-lasting suppression effects has led elsewhere to a reconsideration of the function of inhibition (see Stoltzfus et al., 1993; Tipper et al,, 1991). A mechanism that served concurrent selection of a target by suppressing distraction would have no reason to continue to dampen the representations of distractors once selection had occurred. Rather, by virtue of its sustained nature, negative priming would seem to be an index of an inhibitory function which, once engaged, serves to prevent dampened representations from regaining access to response effectors. As such, inhibition would enable selected representations to build coherence across time, unmolested by competition from rejected candidates.

Of course, this assumes that negative priming actually reflects the action of an inhibitory mechanism. An alternative view is that location negative priming results from featural mismatches that occur across prime and probe trials (Park \& Kanwisher, 1994). Recently, however, one research group (Milliken, Tipper, \& Weaver, 1994; Tipper, Weaver, $\&$ Milliken, 1995) has demonstrated that although feature mismatches can produce negative priming under some conditions, they do not under others (see also May et a1., 1995, for a similar view). In the "standard" conditions of the location task, such as those used in the present work, performance determinants are unclear and thus the present data cannot be taken to distinguish between the two views. However, if retrieval of object features that mismatch with the current display were critical to determining negative priming in the present work, one might have expected to see reliable RSI effects. That is, as in episodic retrieval views, object mismatches should have a larger effect when those mismatches are more, rather than less, easily retrieved. Since we found little evidence for RSI effects, our data might be taken to suggest that spatial mismatches were not contributing substantially to the present effects.

We note, in closing, that although our data do call into question the robustness of Neill's findings (Neill \& Valdes, 1992; Neill et al., 1992), the patterns observed in the raw data are arguably consistent with Neill's views. Our own attempt to account for the different patterns of negative priming decay in within versus between subjects by manipulating stimulus exposure duration was not successful; neither long nor short exposure durations produced substantial decay of negative priming. That said, we would caution negative priming researchers that unless such decay effects can be more convincingly replicated, the Neill et al. data do not provide enough evidence to suggest that episodic retrieval inevitably determines negative priming.

However, the present findings should not be taken to imply that episodic retrieval never occurs in the context of negative priming tasks. Both in our recent work (Kane, May, Hasher, Rahhal, \& Stoltzfus, in press; May et al., 1995) and in that of others (Milliken et al., 1994; Tipper et al., 1995), there is good evidence that episodic retrieval can indeed contribute to negative priming in some contexts. May et al. (1995) argue that the negative priming effect can be caused by two processes: (1) inhibition accorded to a rejected distractor; and (2) episodic retrieval. For example, Kane et al. (in press) report heightened negative priming whenever information on a prime trial is particularly useful to a participant on a test trial, as occurs when the test display is degraded. This we have argued, engages a retrieval process to help resolve the contents of the present trial: In experimental contexts in which the stimulus sometimes repeats as a target or distractor across trials, the retrieval of prime-trial information will sometimes be useful in determining the identity of a visually degraded probe target. Episodic retrieval is also induced when negative priming trials occur among a large number of "repeated-target" trials (in which the target stimulus is identical across trials), because use of the prior trial's information will most often facilitate performance, although, of course, it disrupts performance on the small proportion of negative priming trials (see Kane et al., in press). Finally, in location tasks, precuing manipulations that give participants advance warning about the color or identity of the upcoming target also appear to induce episodic retrieval (Milliken et al., 1994). By this view, episodic retrieval and resulting conflict in response codes can play a role in influencing performance on negative priming trials.
However, the work by Kane et al. (in press) and Milliken et al. (1994) suggest that episodic retrieval contributes to negative priming only under some conditions, leaving others in which negative priming is an index of inhibition accorded to selected-against distractors. According to Kane et al., episodic retrieval is not a purely "automatic" process (as was originally proposed; see Neill \& Valdes, 1992; Neill et al., 1992); rather, it requires particular experimental circumstances to occur for retrieval processes to be elicited (see May et al., 1995; Kane et al., in press). We would argue that until stronger evidence can be gathered, episodic retrieval should not be considered a causal factor of the negative priming effects observed in "standard" procedures such as those used here (in contrast to those used by Milliken et al.). Thus, we suggest that, in the experiments presented herein, the negative priming effect resulted from inhibition. As such, inhibition is robust and long lasting.

\section{REFERENCES}

BAdDeley, A. D. (1976). The psychology of memory. New York: Basic Books.

CONNELLY, S. L., \& HASHER, L. (1993). Aging and inhibition of spatial location. Journal of Experimental Psychology: Human Perception \& Performance, 19, 1238-1250.

DeSchePper, B., \& Treisman, A. (1991, November). Novel visual shapes in negative priming. Paper presented at the meeting of the Psychonomic Society, San Francisco.

Educational Testing Service (1976). Kit of factor-referenced cognitive tests. Princeton, NJ: Author.

Fox, E. (1995). Negative priming from ignored distractors in visual selection: A review. Psychonomic Bulletin \& Review, 2, 145-173.

Hasher, L., Stoltzfus, E. R., Zacks, R. T., \& Rypma, B. (1991). Age and inhibition. Journal of Experimental Psychology: Learning, Memory, \& Cognition, 17, 163-169.

Kane, M. J., HASher, L., STOltZfus, E. R., ZACks, R. T., \& CONNElly, S. L. (1994). Inhibitory attentional mechanisms and aging. Psychology \& Aging, 9, 103-1 12.

Kane, M. J., May, C. P., Hasher, L., Rahhal, T., \& Stoltzfus, E. R. (in press). Dual mechanisms of negative priming: Evidence from aging studies. Journal of Experimental Psychology: Human Perception \& Performance.

Maxwell, S. E., \& Delaney, H. D. (1990). Designing experiments and analyzing data: $A$ model comparison perspective. Belmont, $\mathrm{CA}$ : Wadsworth.

May, C. P., KANe, M. J., \& Hasher, L. (1995). Determinants of negative priming. Psychological Bulletin, 118, 35-54.

Milliken, B., TipPer, S. P., \& Weaver, B. (1994). Negative priming in a spatial localization task: Feature mismatching and distractor inhibition. Journal of Experimental Psychology: Human Perception \& Performance, 20, 624-646.

NEILL, W. T. (1977). Inhibitory and facilitatory processes in attention. Journal of Experimental Psychology: Human Perception \& Performance, 3, 444-450.

NeILL, W. T., LissNeR, L. S., \& BECK, J. L. (1990). Negative priming is same-different matching: Further evidence for a central locus of inhibition. Perception \& Psychophysics, 48, 398-400.

NeILL, W. T., \& VALDES, L. A. (1992). The persistence of negative priming: Steady-state or decay? Journal of Experimental Psychology: Learning, Memory, \& Cognition, 18, 565-576.

Neill, W. T., Valdes, L. A., \& Terry, K. M. (1995). Selective attention and the inhibitory control of cognition. In F. N. Dempster \& C. J. Brainerd (Eds.), Interference and inhibition in cognition (pp. $207-$ 261). New York: Academic Press.

Neill, W. T., Valdes, L. A., Terry, K. M., \& Gorfein, D. S. (1992). The persistence of negative priming: II. Evidence for episodic trace retrieval. Journal of Experimental Psvchology: Learning, Memory, \& Cognition, 18, 993-1000.

NeILL, W. T., \& WestberRY, R. L. (1987). Selective attention and the suppression of cognitive noise. Journal of Experimental Psychology: Learning, Memory, \& Cognition, 13, 327-334.

PARK, J., \& Kanwisher, N. (1994). Negative priming for spatial locations: Identity mismatching, not distractor inhibition. Journal of Experimental Psychology: Human Perception \& Performance, 20, 613623. 
Stoltzfus, E. R., Hasher, L., Zacks, R. T., Ulivi, M. S., \& GoldSTEIN, D. (1993). Investigation of inhibition and interference in younger and older adults. Journal of Gerontology, 48, P179-P188.

TIPPER, S. P. (1985). The negative priming effect: Inhibitory priming by ignored objects. Quarterly Journal of Experimental Psychology, 37A, 571-590.

Tipper, S. P., Brehaut, J. C., \& Driver, J. (1990). Selection of moving and static objects for the control of spatially directed action. Journal of Experimental Psychology: Human Perception \& Performance, 16, 492-504.

TIPPER, S. P., \& CRanston, M. (1985). Selective attention and priming: Inhibitory and facilitatory effects of ignored primes. Quarterly Journal of Experimental Psychology, 37A, 591-611.

TIPPER, S. P., \& MCLAREN, J. (1990). Evidence for efficient visual selectivity in children. In J. T. Enns (Ed.), The development of attention Research and theory (pp. 197-210). Amsterdam: Elsevier, NorthHolland.

Tipper, S. P., Weaver, B., Cameron, S., Brehaut, J. C., \& Bastedo, J. (1991). Inhibitory mechanisms of attention in identification tasks: Time-course and disruption. Journal of Experimental Psychology: Learning, Memory, \& Cognition, 17, 681-692.
TipPer, S. P., Weaver, B., \& Milliken, B. (1995). Spatial negative priming without mismatching: Comment on Park and Kanwisher. Journal of Experimental Psychology: Human Perception \& Performance, 21, 1220-1229.

\section{NOTES}

1. In all of the analyses of variance reported herein, we tested for performance differences between the two university populations; except for higher performance on the vocabulary test shown by Duke students, no other comparison was significant.

2. Both here and in the second experiment, trials were also included in which distractors did not appear. These data are not germane to present concerns. For comparable findings, however, see Connelly and Hasher (1993).

3. As will become clear, this analysis was not appropriate for the data in Experiment 1 since the subjects initiated each prime trial, resulting in an unknown interval preceding each prime trial.

(Manuscript received April 25, 1995; revision accepted for publication September 30, 1995.) 